\title{
A Intenção Nacionalista na Canção de Câmera: Toada P'ra Você de Oscar Lorenzo Fernandez
}

\author{
Nationalist Intention in the Art Song: \\ “Toada P'ra Você" by Oscar Lorenzo Fernandez
}

\author{
Achille Picchi \\ UNESP - Universidade Estadual Paulista \\ achillepicchi@gmail.com
}

Resumo: Este artigo trata da canção de câmera Toada P'ra Você op.56, de Oscar Lorenzo Fernandez, uma das essenciais canções de câmera do repertório brasileiro. Propõe uma análise musical, textual e texto-música, do pianismo e da vocalidade, metodologia original decalcada de muitas fontes e sintetizada há muitos anos de pesquisa por este pesquisador, sobre a canção de câmera nacional. Chega a alguns pontos de reflexão sobre as relações texto-música e realização da canção e sua respectiva interpretação.

Palavras-chave: música brasileira; canção de câmera; análise de canção; Lorenzo Fernandez.

\begin{abstract}
This article deals with the art song Toada P'ra Voce, op.56, composed by Oscar Lorenzo Fernandez, one the most important works in the Brazilian art song vocal repertoire. It proposes an analysis of the musical text, thelyrics and the relation between text and music, besides a view of idiomatic piano and vocal techniques, according to an original methodology developed by the author for the research-field of Brazilian art song. It proposes some reflections about a performance based on text-music relationships and the interpretation of the art song.
\end{abstract}

Keywords: Brazilian music; art song; song analysis; Lorenzo Fernandez. 


\section{1 - Introdução}

A canção de câmera ${ }^{1}$ Toada P'ra Você op.56, de Oscar Lorenzo Fernandez (1897-1948), escrita sobre versos de Mário de Andrade (1893-1945), foi completada e publicada em 1928, mesmo ano, curiosamente, no qual vem a lume o importante libelo nacionalista - espécie de catecismo em prol da composição nacional $^{2}$ - escrito pelo mesmo Mário de Andrade, o Ensaio Sobre a Música Brasileira (Andrade 1962).

A afiliação inequívoca a esse texto por parte de Lorenzo Fernandez é conhecida e notável. Não, talvez, de maneira imediata, de forma que Toada P'ra Você se filiasse igualmente como inspiração, já se vê; mas pela perspectiva da filiação nacionalista do compositor ao longo de sua vida criativa e, principalmente, sua inclinação como ideário.

A partir da sua estreia (que se deu no mesmo ano de sua composição), Toada P'ra Você teve grande aceitação entre cantores, críticos e público igualmente. Vendeu, em sua primeira edição, um milhar de exemplares, feito editorial incomum então, tratando-se de uma canção de câmera ${ }^{3}$.

Os pontos de contato com a música popular ("popularesca" ou urbana, como queria Mário de Andrade ${ }^{4}$ ) não são poucos, sequer insignificantes. De fato, relacionam-se muito ao universo simbólico onde essa música sempre se movimentou.

Entretanto, não se pode dizer que a canção Toada P'ra Você tenha ficado "popular" enquanto canção de câmera; mas o quantum de afirmação folclórica embutida numa época de sedimentação nacionalista-modernista, com a valorização do rural enquanto originário da identidade nacional e suas relações com o popular urbano explica, em grande medida, sua popularidade. Esta popularidade se estende a intérpretes, críticos e público em apresentações e gravações, com uma certa constância; e, a se pensar nos mecanismos que cristalizam uma tradição ${ }^{5}$, transformou-se no que se pode chamar de repertório essencial da "legítima" canção de câmera brasileira. Guardadas as proporções, até mesmo o "legítimo" lied nacional - embora, talvez, não tão distante assim do que se possa entender como o lied originalmente foi entendido, já que Alberto Nepomuceno introduzira esse viés, através do Romantismo em sua visada composicional, para a canção de câmera em português.

\footnotetext{
1 Sobre a identificação e categorização da canção de câmera como obra escrita para voz e piano, tal como aqui tratado, remeto a Picchi, 2010.

${ }^{2}$ Cf. Picchi, 1996.

${ }^{3} \mathrm{E}$, diríamos, mesmo atéhoje...

" Mário de Andrade fazia a distinção "música popular" essencialmente para o folclore e "música urbana ou popularesca" para a música popular como hoje a designamos.

${ }_{5}^{5}$ Cf., por exemplo, em Hobsbawn e Ranger, 1989.
} 
Pelo menos um comentarista, em sua época, e até posteriormente outros, chegaram a gerar propostas um tanto ufanistas, de rasa expressão, até mesmo sobre compositores de importância para o movimento nacional tais como Camargo Guarnieri (1907-1993), Francisco Mignone (1897-1986), dentre alguns outros $^{6}$. Isso provavelmente - como veremos adiante em nossa análise - foi gerado por suas características composicionais que se adequam ao pensamento nacionalista imaginado por um movimento de época que se suporta através tanto da ideologia (razão política), como do romantismo (razão psicossocial).

O poema musicado, de um poeta, musicólogo e crítico modernista, mentor do nacionalismo na época, Mário de Andrade, foi originalmente publicado como Rondó P'ra Você, e coligido no livro Clã do Jabuti editado em 1924. A mudança, efetuada pelo compositor (de Rondó para Toada) está estreitamente ligada à expressão musical e, naturalmente, à leitura composicional (no sentido textomúsica, o qual comentaremos adiante) feita pelo compositor, com evidente intencionalidade e também evidente claridade ideológica. E são esses, de fato, os vieses que perpassarão a ideia de nacional residente na canção, que parecerão estar presentes e, até, serem óbvios na observação de comentadores e pseudoanalistas que não se apercebem da armadilha que é a literatice na pseudoanálise de uma realização composicional de texto-música numa canção de câmera sem o apoio substancioso de uma análise efetiva.

No caso do nacional em Toada P'ra Você pode-se dizer que Lorenzo Fernandez, sabedor e correspondendo às ideias de Mário de Andrade sobre a utilização do folclore no estabelecimento do nacional na música brasileira aquilo que, então, caracterizaria a brasilidade - num momento crítico de afirmação identitária, usa de recursos como a utilização de um ostinato, reconhecível como toada, e muda o título do poema referencialmente, portanto indo em direção à imagética sub-reptícia representativa intencional dessa ideia do nacional. O compositor lança mão desses recursos principalmente no tratamento que dispensa ao texto-música, campo vasto de investigação e de afirmação da canção de câmera, que reflete no entendimento tanto de sua constituição como de sua importância objetiva para o compositor.

Trata-se, o texto-música, no caso da canção de câmera, de relação indissociável entre o texto a ser musicado, que é lido 'musicalmente' pelo compositor com essa intenção e a musicação, ou seja, a aposição dessa leitura com

\footnotetext{
6 Segundo Mariz, 1985, p.219, essas propostas levaram a um instantâneo "voceísmo" na música vocal de câmera brasileira, opinião que, francamente, consideramos eivada de observação assistemática e pouco musicológica. A relação de ideias "você" e o nacionalismo em con strução naquele momento são, certamente, invenção do musicólogo devida àquela observação, provavelmente, e a uma espécie de hipostasia histórico-posterior sem qualquer fundamento, fato que nos leva a acreditar que não deva ser levada para além de uma opinião curiosa.
} 
intencionalidade a um texto musical. A leitura a que procede o compositor previamente à existência dessa totalidade chamada canção de câmera - ou seja, linha musical com texto aposto, pianismo ${ }^{7}$, vocalidade, imbricados indivisivelmente -, envolve não somente o revestimento musical, mas a adaptabilidade entre música e texto.

Assim, texto-música amplia-se, para a definição de canção de câmera, e inclui fundamentalmente a parte pianística como duas facetas, o código instrumental decodificado, sua escrita e o "por detrás do código" a ser decodifica do, sua escritura, indo além até a vocalidade. Entra, nessa equação, um fator importante, tanto para a realização composicional como interpretativa da canção de câmera, a intencionalidade.

A intenção, de um modo geral, se traduz por uma ação sobre escolhas. Ou, como diria Searle (1985, p.103), "uma ação intencional (ou a intencionalidade) é simplesmente a realização de condições de satisfação de uma intenção". No caso da música - e especialmente da canção de câmera - essa realização de condições de satisfação de uma intenção (que envolve volição e ação, igualmente), deixa rastros: a escrita. O que, afinal, abre as portas para o estudo analítico e condições de conclusões para perceber através dela, ou seja da escrita, os indícios que apontem para as condições de satisfação intencional composicional do textomúsica. Em suma, decisões composicionais.

No caso específico de Toada P'ra Você, torna-se crucial o caráter dessas decisões composicionais, para o estabelecimento geral do lied nacional, visto que existe, embutido nelas - e inegavelmente exercido musicalmente -, a vontade de que seja nacional.

Luis Heitor Correa de Azevedo afirmava que o lirismo íntimo e afetivo e de afirmação nacional encontra-se principalmente na canção de câmera ${ }^{8}$. Além disso, afirma, com sabor marioandradiano, que na canção de câmera nacional, "no contorno melódico, como em certas tendências rítmicas, já entrevemos aquelas 'constâncias' que mais tarde hão-de (sic) marcar tão caracteristicamente a música brasileira no sentido nacional" 9 .

Considerando-se o nacional na música brasileira, para se bem compreender a canção de câmera como seu símbolo, torna-se a Mário de Andrade que referia o nacional na música brasileira como sendo a introjeção do conhecimento da música popular (leia-se folclórica) em sua essência para que,

\footnotetext{
${ }^{7}$ Sobre este item cf. Picchi, 2010.

${ }^{8}$ Azevedo, Luis Heitor Correa de. 1947. La música en Brasil. In: Cuadernos Americanos. México, ano VI, vol. XXXIII, maio-junho, p.271.

${ }^{9}$ Azevedo, Luis Heitor Correa de. 1948. Canções Brasileiras. In: Brasil Cultural, Porto, ano II, agosto, p.10-15.
} 
em sua inconsciência, o compositor fosse brasileiro em tudo o que criasse ${ }^{10}$. Uma tarefa, assim como um objetivo, românticos e idealistas, já se vê.

Como bem reflete Squeff (1982, p.17) sobre esse folclorismo telúrico de raiz, o Brasil "é extenso demais e complexo em demasia nas suas expressões folclóricas para que um único modelo defina sua 'especificidade'”. E sugere:

O pathos de uma época está mais na música que em outras manifestações artísticas. [...] A música é apenas tem po: por isso, o mais alto nível de uma emotividade que se faz razão tanto na medida em que é absorvida, memorizada ou racionalizada, como no estágio em que sugere um pathos que pode ser determinado historicamente. Ora, se o elemento que entra na música nacionalista é precisamente o ethos - há que se considerar o problema do pathos da música como uma questão muito específica. Se o pathos musical pode conduzir ao ethos, é porque o pathos é também ethos" (Squeff 1982, p.16).

Assim pensando, pode-se ver o nacionalismo musical como fundamentalmente ideológico, uma visão de mundo, uma maneira de sentir e realizar o zeitgeist centrado, a cada momento, no tecido histórico vivido.

A situação do nacionalismo é inelutavelmente política e residirá sempre na apropriação conceitual por grupos para sua exteriorização. Veja-se o caso da síncopa na música. Acaba por ser uma metáfora nacional integrada pelos que advêm da manifestação vista e registrada por uma classe ou grupo que a observa, relacionada ao ethos geral do país musical. Porém, manter-se-á sempre o problema para a síncopa: em si mesma não representa nada além de uma figura rítmico-musical; para ser representativa ou simbólica haverá de alguma forma ser situada e funcional num determinado contexto.

Chega-se, assim, a um foco nodal do nacionalismo musical, mormente aquele pós-1922: a representação do nacional buscada em usos e processos pelo compositor imbuído da ideia de que há essa possibilidade representacional. Tal é o caso da intencionalidade da canção de câmera Toada P'ra Você e de Oscar Lorenzo Fernandez.

\section{2 - Análise}

A metodologia de análise da canção de câmera utilizada divide-se em análise musical, análise textual e texto-música, pianismo e vocalidade. Essa metodologia de Picchi foi descrita e empregada em tese e artigos por (Picchi 2010, 2011, 2012).

${ }^{10}$ Andrade, Mario de. 1962. Ensaio Sobre a Música Brasileira. São Paulo: Martins. 
Sucintamente a análise musical envolve a descrição e amostragem do material, análise da estrutura contendo Contorno da Dimensão Horizontal, com a realização de uma análise redutora gráfica baseada em Schenker/Salzer, Condução da Dimensão Vertical e ritmo, análise textural.

Em seguida faz-se a análise textual dos eixos poéticos, contendo estrutura rítmica, estrutura métrica, estrutura estrófica e estrutura sônica, todas com conclusões sintetizadas em tabelas progressivas.

A análise texto-música que se processa em seguida é a mais importante para a realização da compreensão da leitura efetuada pelo compositor em relação à realização da canção de câmera. Contém uma descrição do contexto do poema, uma análise relacional de eixos poéticos e canção e situação métrico-prosódica em relação à composição, também demonstradas em tabelas comparativas.

Em seguida procede-se a uma análise do 'pianismo', conceito que foi também já esmiuçado em tese e artigos. Sintetizando rapidamente, o pianismo contempla o procedimento de atuação do piano para além da simples escrita/código do instrumento, em relação ao texto-música da canção. Assim, utilizando uma adaptação do conceito de escritura proposto por Jacques Derrida $^{11}$, nos propomos a mostrar as duas vertentes dialéticas escrita-escritura (as quais fizemos menção mais acima) na parte pianística, ou seja, o código e o que a execução interpretativa de fato mostra 'por detrás' do código, como elementos de fundamentação do suporte e/ou caminho pianístico com a canção.

Isto quer dizer que para além do fato consensual do pianístico da parte para o instrumento, tem-se o suporte, psicológico, imagético, a realização de comentário ao texto-música, o procedimento evocativo, e etc., sendo analisado caso a caso conforme a canção, porque tudo isto é suposto existir a partir da intencionalidade composicional. Dessa forma, o pianismo de alguma maneira acompanha a leitura do texto procedida pelo compositor, leitura, esta, musical; e destarte a envolve num todo. Daí a estreita correlação texto-música se tornar sempre o cerne da canção de câmera, mas não só para a linha vocal senão para aquela e a parte pianística totalmente imbricadas.

Uma última visão analítica se dá em relação à vocalidade, ou seja, o caminho de realização vocal não somente do ponto de vista da execução interpretativa da voz, suas técnicas e limitações e/ou vicissitudes, mas também, adequações e possibilidades para além da escrita, portanto escrituras, como campo aberto e enorme de criações.

Expressa-se aqui a ideia de que, como dito acima, a análise substanciosa possibilita e viabiliza muitas possibilidades interpretativas e visões de entendimento da canção de câmera; no entanto aqui se aplica essa metodologia

${ }^{11}$ Especialmente em Gramatologia (Derrida 2008). 
como introdução a esse conhecimento, com posterior remissão à nossa pesquisa, sempre em andamento.

\section{1. - Análise Musical}

Considerando o material de Toada P'ra Você, ele é constituído pela escala de Lá bemol Maior, que realiza a tonalidade de Lá bemol Maior.

Numa redução gráfica que se realize da peça, onde mostramos apenas os centros, os principais e secundários e outros pequenos detalhes de continuida de, como notas de passagem que podem, eventualmente, se configurar em voiceleading, (claramente decalcado e simplificado de Schenker a Salzer), para o Contorno de Dimensão Horizontal na parte vocal, se nos apontam dois centros principais, o Sol e o Fá, mesmo que de várias maneiras o Sol se comporte como appoggiatura do centro Fá. Os centros principais, nesta ideia de redução, são as notas que preponderam durante toda a peça e que são mostradas com um traço contínuo no gráfico.

Na Contorno de Dimensão Horizontal da parte do piano também temos os centros principais de Sol e Fá, mas constituem-se centros secundários o $\mathrm{Mi}$ bemol e o Lá bemol, o que nos remete ao quinto grau e ao primeiro grau da tonalidade da peça, confirmando a tonalidade de Lá bemol Maior.

Os centros secundários seriam aquelas notas que têm preponderância, em toda a peça, mas com dependência aos centros principais sem a mesma importância frasal ou vertical.

A peça é motívica, com variações e variantes, segundo o conceito emitido por Schoenberg (1996), como se pode verificar na Figura 1:
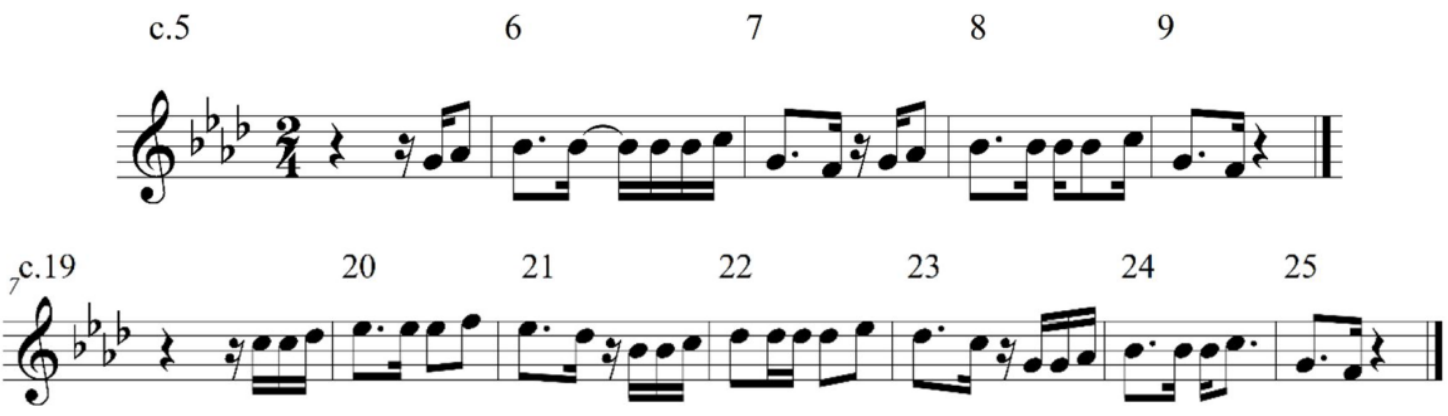

Figura 1: Motivo, variações e variantes de Toada P'ra Você.

A Condução de Dimensão Vertical, embora sendo tratada de maneira polifônica, soa homofonicamente, como se fosse um contraponto de primeira espécie entre as quatro vozes do piano. Este é um fato curioso que poderia nos 
remeter à ideia de que o nacionalismo de primeira hora, no Brasil, se voltou para o folclore como origem e este, fundamentalmente, é melódico.

O ritmo harmônico da peça é bastante lento, isto é, pouco muda, especialmente em relação à ideia de ostinato que constitui o desenvolvimento dela.

O esquema formal constitui-se de uma pequena introdução pianística (c.14), A (c.5-18), B (c.19-27), pequena ponte harmônica (c.27-30), novamente A (c.3144), novamente B (c.45-53) e pequena coda (c.54-58).

Quanto ao ritmo temos o importante uso do ostinato, que, nesse caso, é construtor da canção e inclusive lhe dá justificativa quanto ao título e a necessidade do compositor em trocar o original Rondó P'ra Você do poeta para Toada P'ra Você. Na verdade, o uso do ostinato, que condiciona motivicamente a construção da peça é um procedimento que se tornou comum aos compositores nacionalistas ${ }^{12}$.

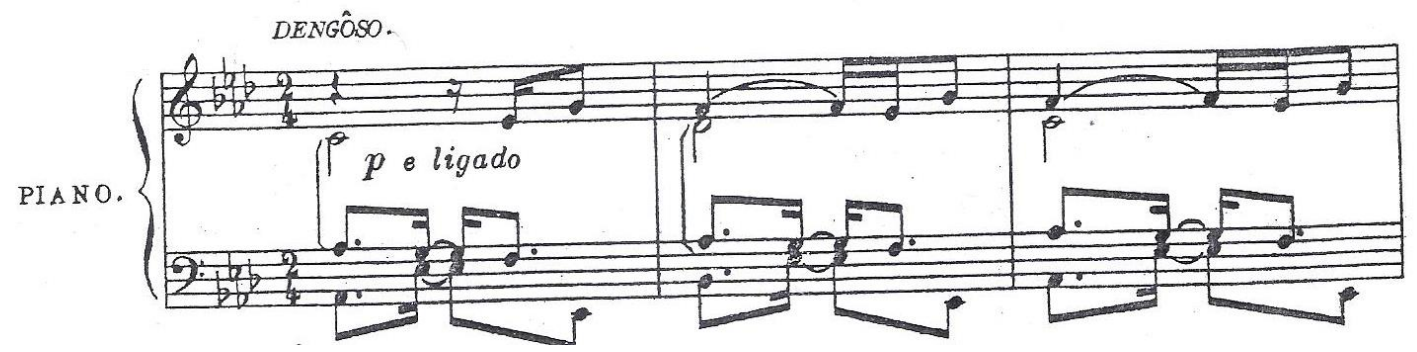

Figura 2: Ostinati na parte do piano em Toada P'ra Você.

Visto que sempre o compositor considerou a melodia acompanhada tanto na parte vocal como na parte superior do piano, a relação e condução texturais se mantêm. Entretanto, o curioso é que a linha pianística se comporta polifonicamente enquanto escrita, porém a sonoridade $-\mathrm{e}$, portanto, o tratamento da escritura - se comporta harmonicamente.

\section{2 - Análise Textual e Texto-Música}

Para a análise textual considera-se quatro estruturas de construção poética: a estrutura rítmica, a estrutura métrica, ambas interligadas; a estrutura estrófica, de importância para a construção formal da canção; e a estrutura sônica, onde se consideram as coincidências sonoras, inclusive rimas, para a utilização texto-música. Tanto na estrutura rítmica como na métrica do poema, nota-se o trabalho poético de tentar conformar o poema ao octossílabo, constituição poética aliás muito importante para a poesia popular do Brasil, especialmente na região nordeste. Veja-se a Tabela 1 que resume a Estrutura Rítmica:

12 Ver Picchi 2011, p.1617-1622. 


\begin{tabular}{|c|c|c|}
\hline ICTOS & TÔNICA DO VERSO & $\begin{array}{c}\text { RÍTMICA } \\
\text { FRASAL/CANÇÃO }\end{array}$ \\
\hline $\begin{array}{c}\text { De você, Rosa eu não queria } \\
3-4-8\end{array}$ & $3^{\circ}$ e $8^{o}$ & $2^{\circ}, 3^{\circ}$ e $8^{\circ}$ \\
\hline $\begin{array}{c}\text { Receber somente este abraço } \\
3-5-8\end{array}$ & $3^{\circ}$ e $8^{o}$ & $2^{\circ}, 3^{\circ}, 6^{o}$ e $8^{o}$ \\
\hline $\begin{array}{l}\text { Tão devagar que você me dá, } \\
4-(7)-9\end{array}$ & $4^{\circ}$ e $9^{o}$ & $2^{\circ}, 4^{\circ}, 6^{o}$ e $9^{o}$ \\
\hline $\begin{array}{l}\text { Nem gozar (sic) somente esse beijo } \\
3-5-8\end{array}$ & $5^{\circ}$ e $8^{o}$ & $2^{\circ}, 6^{\circ}$ e $8^{\circ}$ \\
\hline $\begin{array}{l}\text { Tão molhado que você me dá. } \\
3-9\end{array}$ & $3^{\circ}$ e $9^{o}$ & $1^{\circ}, 3^{\circ}, 6^{o}$ e $9^{o}$ \\
\hline $\begin{array}{c}\text { Eu não queria só porquê } \\
4-(6)-8 \\
\end{array}$ & $4^{\circ}$ e $8^{o}$ & $4^{\circ}, 6^{\circ}$ e $8^{o}$ \\
\hline $\begin{array}{l}\text { Por tudo quanto você me fala } \\
\qquad 2-4-(7)-9\end{array}$ & $2^{\circ},\left(7^{\circ}\right), 9^{\circ}$ & $4^{\circ}, 7^{\circ},\left(8^{\circ}\right)$ e $9^{o}$ \\
\hline $\begin{array}{l}\text { Já reparei que no seu peito } \\
44-8 \\
\end{array}$ & $4^{\circ}$ e $8^{o}$ & $4^{\circ}, 6^{\circ},\left(7^{\circ}\right)$ e $8^{o}$ \\
\hline $\begin{array}{l}\text { Soluça um coração bem feito } \\
22-(6)-8\end{array}$ & $2^{o}$ e $8^{o}$ & $4^{\circ}, 6^{\circ},\left(7^{\circ}\right)$ e $8^{o}$ \\
\hline $\begin{array}{l}\text { De você } \\
2-3 \\
\end{array}$ & 3 & $2^{\circ}$ e $3^{o}$ \\
\hline $\begin{array}{c}\text { Pois então eu imaginei } \\
3-8 \\
\end{array}$ & $3^{\circ}$ e $8^{o}$ & $3^{\circ}, 4^{\circ}, 8^{\circ}$ \\
\hline $\begin{array}{l}\text { Que junto com esse corpo magro } \\
\text { 2-(6)-9 [ou, considerando a ectlipse }{ }^{13} \mathrm{de} \\
\text { com esse em co'esse, 2-(5)-8] }\end{array}$ & $2^{\circ}$ e $9^{\circ}$ & $4^{\circ}, 5^{\circ}$ e $9^{o}$ \\
\hline $\begin{array}{c}\text { Moreninho que você me dá, } \\
3-7-9\end{array}$ & $3^{\circ}$ e $9^{\circ}$ & $1^{\circ}, 3^{\circ}, 7^{\circ}$ e $9^{o}$ \\
\hline $\begin{array}{l}\text { Com a boniteza a faceirice } \\
\text { 5-9 [ou, novamente usando a ectlipse } \\
\left.\text { para com } a \text { em } c o^{\prime} a, 4-8\right]\end{array}$ & $5^{\circ}$ e $9^{\circ}$ & $1^{\circ}, 5^{\circ}, 6^{\circ}$ e $9^{\circ}$ \\
\hline $\begin{array}{l}\text { A risada que você me dá } \\
\qquad 3-7-9\end{array}$ & 3 e $9^{\circ}$ & $1^{\circ}, 3^{\circ}, 6^{\circ}$ e $9^{\circ}$ \\
\hline $\begin{array}{l}\text { E me enrabicham como o quê, } \\
4-8\end{array}$ & $4^{\mathrm{o}}$ e $8^{\mathrm{o}}$ & $4^{\underline{o}}, 6^{\circ}$ e $8^{\underline{o}}$ \\
\hline $\begin{array}{c}\text { Bem que eu podia possuir também } \\
\text { 4-8-10 (ou, considerando a sinérese em } \\
\text { po-dia e em pos-suir 4-6-8) }\end{array}$ & $5^{\circ}, 8^{\circ}$ e $10^{\circ}$ & $\begin{array}{c}4^{\circ}, 7^{\circ} \text { e } 9^{\circ}, \\
\text { com sinérese }\end{array}$ \\
\hline $\begin{array}{l}\text { O que mora atrás do seu rosto, Rosa, } \\
3-5-8-10\end{array}$ & $5^{\circ}, 8^{\circ}$ e $10^{\circ}$ & $1^{\mathrm{o}}, 5^{\mathrm{o}}, 6^{\circ}$ e $10^{\mathrm{o}}$ \\
\hline
\end{tabular}

${ }^{13}$ Ectlipse: "elisão do fonema nasal, não sendo obrigatório o uso de apóstrofo para demonstralo" (Tavares p. 186) 


\begin{tabular}{|c|c|c|}
\hline $\begin{array}{c}\text { O pensamento, a alma, o desgosto, } \\
4-6-8 \\
\text { (considerando as elisões }{ }^{14} \\
\text { pen-sa-men-toaal-mao) }\end{array}$ & $4^{\circ},\left(6^{\circ}\right)$ e $8^{\circ}$ & $\begin{array}{l}4^{\underline{\mathrm{o}}}, 6^{\mathrm{o}}, 7^{\mathrm{o}} \text { e } 9^{\underline{\mathrm{o}}} \\
\text { (desconsiderando } \\
\text { elisão pensamento a) }\end{array}$ \\
\hline De você. & 3 & $2^{\circ}$ e $3^{o}$ \\
\hline
\end{tabular}

Tabela 1: Estrutura Rítmica de Rondó Pr'a Você e Toada P'ra Você.

Na Tabela 1 pode-se observar que essa ideia de conformação poética ao octossílabo, que faria de Rondó P'ra Você um poema isorrítmico, nem sempre foi lida musicalmente pelo compositor, como por exemplo nos versos 12, 14, 17 e 19 - e, portanto, ele é um poema heterorrítmico.

Agora veja-se a Tabela 2, de Estrutura Métrica:

\begin{tabular}{|c|c|}
\hline Pés Métricos & Células Métricas \\
\hline $\begin{array}{c}\text { De você, Rosa, eu não queria } \\
--/ /---/\end{array}$ & Anapesto + troqueu + péon quarto \\
\hline $\begin{array}{c}\text { Receber somente este abraço } \\
--/-/--/-\end{array}$ & Anapesto + anfíbraco + anfibraco \\
\hline $\begin{array}{c}\text { Tão devagar que você me dá, } \\
---/--/ \text {-/ }\end{array}$ & Péon quarto + anapesto + jâmbico \\
\hline $\begin{array}{c}\text { Nem gosar (sic) somente este beijo } \\
--/--/-/-\end{array}$ & Anapesto + anapesto + péon quarto \\
\hline $\begin{array}{c}\text { Tão molhado que você me dá... } \\
\text {--/ ---/ -/ }\end{array}$ & Anapesto + péon quarto + jâmbico \\
\hline $\begin{array}{c}\text { Eu não queria só porquê } \\
---/-/-/\end{array}$ & Péon quarto + jâmbico + jâmbico \\
\hline $\begin{array}{l}\text { Por tudo quanto você me fala } \\
\qquad--/--/-/-\end{array}$ & Péon quarto + anapesto + anfíbraco \\
\hline $\begin{array}{c}\text { Já reparei que no seu peito } \\
---/---/\end{array}$ & Péon quarto + péon quarto \\
\hline $\begin{array}{c}\text { Soluça um coração bem feito } \\
---/ \text {---/ } \\
\end{array}$ & Péon quarto + péon quarto \\
\hline De você. & Anapesto \\
\hline $\begin{array}{c}\text { Pois então eu imaginei } \\
--/---/ \\
\end{array}$ & Anapesto + rípio ${ }^{15}+$ péon quarto \\
\hline $\begin{array}{c}\text { Que junto com esse corpo magro } \\
-/--\mid--/\end{array}$ & Anfíbraco + anfíbraco + anapesto \\
\hline
\end{tabular}

${ }^{14}$ Elisão: absorção de vogais seguidas em palavras contíguas (Tavares, p.186)

${ }^{15}$ Rípio ou cavilha é palavra enxertada mas não necessária num verso a fim de completar-lhe a medida (Tavares p.189).

\section{MUSICA THEORICA}

Revista da Associação Brasileira de Teoria e Análise Musical Journal of the Brazilian Society for Music Theory and Analysis 


\begin{tabular}{|c|c|}
\hline $\begin{array}{c}\text { Moreninho que você me dá, } \\
---/-/-/\end{array}$ & Anapesto + anapesto + jâmbico \\
\hline $\begin{array}{c}\text { Com a boniteza a faceirice } \\
---/ \text {---/ }\end{array}$ & Péon quarto + péon quarto ${ }^{16}$ \\
\hline $\begin{array}{c}\text { A risada que você me dá } \\
--/--/-/\end{array}$ & Anapesto + péon quarto + jâmbico \\
\hline E me enrabicham como o quê, & Péon quarto + péon quarto \\
\hline $\begin{array}{l}\text { Bem que eu podia possuir também } \\
---/--/-/\end{array}$ & Péon quarto + anapesto + jâmbico \\
\hline $\begin{array}{c}\text { O que mora atrás do seu rosto, Rosa, } \\
--/-/--/-/\end{array}$ & Anapesto + jâmbico + anapesto + jâmbico \\
\hline $\begin{array}{c}\text { O pensamento, a alma, o desgosto, } \\
---/-/--/\end{array}$ & Péon quarto + jâmbico + anapesto \\
\hline De você. & Anapesto \\
\hline
\end{tabular}

Tabela 2: Estrutura Métrica de Rondó P'ra Você..

Como se pode ver, muitos são os versos que contêm nove sílabas, assim quebrando a ideia dos oito pés. Entretanto nota-se que sempre o poeta usa o vocábulo "você" nesses casos, o que possibilita pensar numa espécie de aférese ${ }^{17}$, ainda que irregular, visto que não diga respeito a vogal no princípio como a aférese estrita, ao qual se refira ao popular "ocê"18, assim propondo a métrica octossílaba, mesmo que não visível (como, por exemplo, no caso dos versos 3,5,7). Do ponto de vista da leitura do compositor o efeito, como está demonstrado, não foi usado, assim utilizando as nove sílabas para a prosódia vocal musicalmente realizada.

A estrutura métrica mostra uma predominância em número igual da métrica péon quarto (fraca,fraca,fraca,forte) e anapesto (fraca,fraca,forte), e em muitos casos o compositor insere a síncopa nessas métricas e algumas vezes nos anfíbracos (fraco,forte,fraco), mais adequados a ela. Para além disso, utilizando a síncopa como elemento de imaginação simbólico-nacional, essa prosódia em muitos momentos foi readaptada do acentual (acento sobre o pé métrico imediatamente anterior ou posterior ao do poema, por exemplo), caracterizando proposital deslocamento prosódico.

Quanto à estrutura estrófica, o poema se constitui de duas estrofes com dez versos cada, terminando com o verso "De você" igualmente em ambos. O

\footnotetext{
16 Considerando-se a ectlipse em "com a" para "co'a".

17 Aférese: diminuição no princípio do vocábulo. (Tavares, p.189)

18 Hipótese aqui aventada baseada em Tavares (2002, p.189).
} 
compositor de certa forma aproveita essa constituição formal do poeta e estabelece o esquema formal, já mostrado acima, como a cristalizar a ideia popular de repetição, que lhe é característica.

Quanto à estrutura sônica, coincidências sonoras no poema onde também se encontra a rima, o poema é constituído de versos brancos, portanto sem a proposta de rimas; mas o poeta investe em certas assonâncias ${ }^{19}$, como no final do verso 5 da primeira estrofe ("que você me dá...") como a criar simetria poética. Assim também, uma rima eventual nos dois últimos versos da primeira estrofe ("peito" e "feito") e os dois últimos da segunda ("rosto, Rosa" com "desgosto"); e os versos 6 e 10 da primeira e da segunda estrofes ("porquê" e "você"). E naturalmente o verso 10 de cada uma das estrofes, de constituição rítmicométrica diversa dos outros versos octossílabos, mas exatamente iguais, como a justificar formalmente a ideia de rondó, original do poeta e introjetada pelo compositor. Em todos esses casos verifica-se que o compositor investiu em linhas vocais idênticas, assim como em partes pianísticas idênticas, interválica e direccionalmente, mostrando com clareza a intencionalidade da leitura textomúsica que realizou.

\section{3 - Pianismo}

O mais importante procedimento do pianismo em relação ao texto-música nesta canção é o ostinato, ou seja, um recurso que remete a uma ambientação sonoro-harmônica de placidez e pouca movimentação em função muito especialmente da instituição da ideia de toada adstrita ao título.

Tendo a rítmica como escrita, a abertura para escrituras que possam levar ao quasi-parlato, aproveitando as regiões vocais, aos diminuendi e mesmo rallentandi expressivos em função de rubatos expressivos é absolutamente presente e justifica a intencionalidade do compositor no que tange ao aspecto nacional da Toada P'ra Voce.

O quanto isso pareça até certo ponto óbvio, não há, no entanto, qualquer marcação ou apontamento do compositor, destarte sendo possibilitado através da análise anterior e da compreensão do pianismo o que suporte essas visões do texto-música, as quais possam ser adequadas à coerência imprimida à interpretação.

19 Assonância: "sequência de vozes e sílabas semelhantes, mas não idênticas" (Tavares 2002, p.217-218). 


\section{4 - Vocalidade}

A extensão da parte vocal pede Mi bemol-3 até Fa-4, mas a tessitura exige, na maioria da peça, a região Mi bemol-3 - Si bemol-3, considerando-se, assim, a peça como sendo médio-grave, o que talvez requeresse um mezzo soprano mais que um soprano (ou talvez um barítono agudo, cantando uma oitava abaixo, como normalmente acontece quando não se muda a tonalidade). Fato é que dessa forma temos um desenvolvimento da expressão vocal com muita proximidade da prolação mais do que da entoação. Assim, mais um fator de busca e imaginação do processo de intersecção da música popular com a canção de câmera erudita, ou seja, da ambientação da palavra falada como cantada em conjunção à sua compreensão. Isso talvez tenha sido de muito avanço, do ponto de vista sonoro vocal, em sua época, pois ainda predominava (como continuará ainda por bom tempo após esta canção) a maneira de cantar da escola de canto italiana, com todas suas prerrogativas em relação a vogais e nasais.

\section{5 - Reflexões Finais}

Esta pequena mostra de estudo da canção de câmera faz parte de uma contínua pesquisa sobre o processo de compreensão da importância do textomúsica, do pianismo e da vocalidade, formando um todo indivisível, no entendimento da canção nacional, através de interpretações advindas da análise e da vivência.

O que se busca é, cada vez mais, investir e investigar esse objeto tão precioso da nossa cultura musical e procurar fazer evitar, cada vez mais, equívocos e protoanálises, como esses pequenos exemplos escolhidos ao acaso deixam entrever: "a canção traduz, musicalmente, uma certa imagem de melancolia, que parece provocada pela ambiguidade tonal que se pode perceber entre o acompanhamento do piano em Lá bemol maior e a melodia vocal construída sobre a escala de Fá menor" (Pádua 2009, p.205), loquacidade evasiva, visto que não há, como intentamos mostrar via análise, "ambiguidade tonal", algo que não diz realmente nada; "a canção consegue traduzir um estado de espírito característico de uma malícia e sensualidade discreta" (Igayara 1997, p.72); "outro aspecto a ser destacado em sua obra vocal é a habilidade fonética na disposição do texto, fato muito elogiado por Mário de Andrade" (Igayara 1997, p.72), literatices, incluindo equívocos que denunciam falta de efetiva pesquisa científica se se considerar, por exemplo, somente a "habilidade fonética na disposição do texto", uma obviedade obrigatória para qualquer compositor de canções que se preze - e que não traduz qualquer opinião ou mesmo informação útil. 
Para além disso, está em curso ainda um extenso estudo sobre a intencionalidade composicional. Essa intencionalidade está expressa, segundo nossa opinião, no trabalho deixado pelos compositores, e se pode traduzir e perceber muito especialmente por essa metodologia, cada vez mais aprofundada, que propomos e estamos a desenvolver.

O que se quer dizer, muito sucintamente, é que através desse investigar interpretativo, que é a análise (e através de nossa proposta) pode-se divisar de fato as escolhas feitas pelo compositor, interna e externamente à composição, com intencionalidade composicional, deixando inegavelmente um legado testemunhal para que possa conduzir o intérprete em suas escolhas como real corealizador. Não temos dúvidas quanto a isso; entretanto a pesquisa prossegue no sentido de dar fundamento, caráter e substância a esse viés de conhecimento para mais e mais embasar a intepretação, conduzir a uma execução interpretativa e redundar numa performance da canção de câmera brasileira, da qual a Toada P'ra Você, de Oscar Lorenzo Fernandez é uma de suas representantes máximas e fundamentais.

\section{Referências}

1. Andrade, Mário de. 1962. Ensaio Sobre a Música Brasileira. São Paulo: Livraria Martins Editora.

2. Azevedo, Luis Heitor Correa de. 1947. La música en Brasil. In: Cuadernos Americanos. México, ano VI, vol. XXXIII, maio-junho, p.271.

3. Azevedo, Luis Heitor Correa de. 1948. Canções Brasileiras. In: Brasil Cultural, Porto, ano II, agosto, p.10-15.

4. Derrida, Jacques. 2008. Gramatologia. São Paulo: Perspectiva.

5. Hobsbawn, Eric e Ranger (org.). 1997. A Invenção das Tradições. Celina Cardim Cavalcante (trad.). 2 ${ }^{\underline{a}} e d$. Rio de Janeiro: Paz e Terra.

6. Mariz, Vasco. 2002. A canção brasileira. 5a ed. Rio de Janeiro: Nova Fronteira/INL/Pró-memória.

7. Pádua, Mônica Pedrosa. 2009. Imagens de brasilidade nas canções de câmera de Lorenzo Fernandez: uma abordagem semiológica das articulações entre música e poesia. Tese de Doutoramento. Faculdade de Letras da UFMG, Belo Horizonte. 
8. Picchi, Achille G. 1996. Mário Metaprofessor de Andrade. Dissertação de Mestrado. Faculdade de Educação da USP, São Paulo.

9. Picchi, Achille G. 2010. As "Serestas" de Heitor Villa-Lobos: um estudo de análise, texto-música e pianismo para uma interpretação. Tese de Doutoramento. Instituto de Artes da UNICAMP, Campinas.

10. Picchi, Achille G. 2011. O tratamento motívico dos ostinati nas Serestas de Heitor Villa-Lobos. Anais do XXI Congresso da ANPPOM.

11. Picchi, Achille G. 2012. Por uma metodologia de análise da canção de câmera. Anais do Enim, Lisboa, p.121.

12. Searle, John R. 1985. Expression and Meaning: Studies in the Theory of Speech Acts. Cambridge: Cambridge University Press.

13. Schoenberg, Arnold. 1996. Fundamentos da Composição Musical. São Paulo: EDUSP.

14. Squeff, Enio \& Wisnik, José Miguel. 1982. O nacional e o popular na cultura brasileira: Música. São Paulo: Martins Fontes.

15. Tavares, Hênio. 2002. Teoria Literária. Belo Horizonte: Itatiaia.

16. Ygayara, Susana C. 1997. Oscar Lorenzo Fernandez. Revista do Instituto de Estudos Brasileiros, São Paulo, nº-42, p.72. 


\section{$\underline{\text { Anexos }}$}

a.

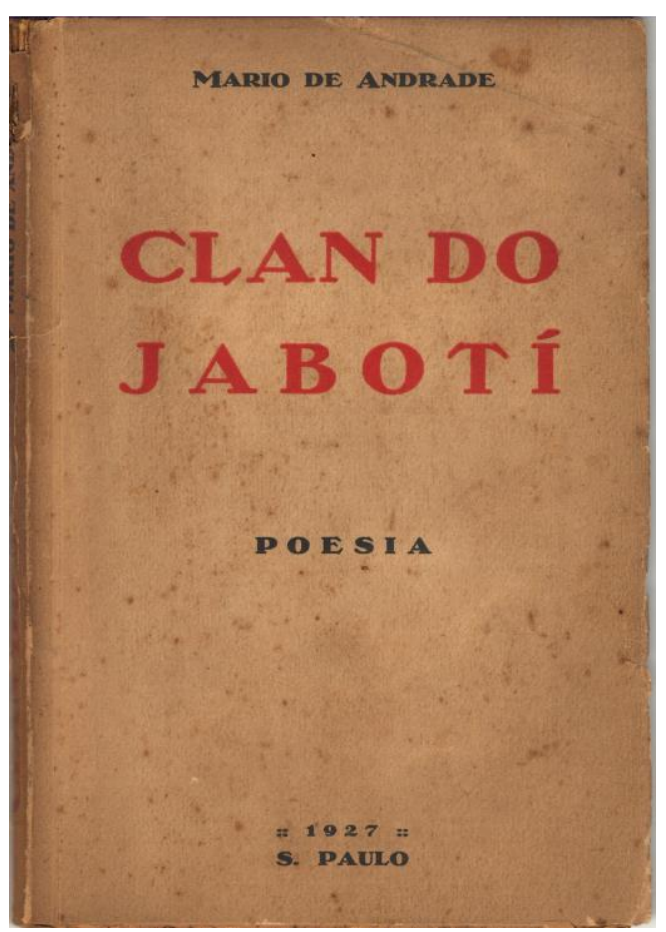

b.

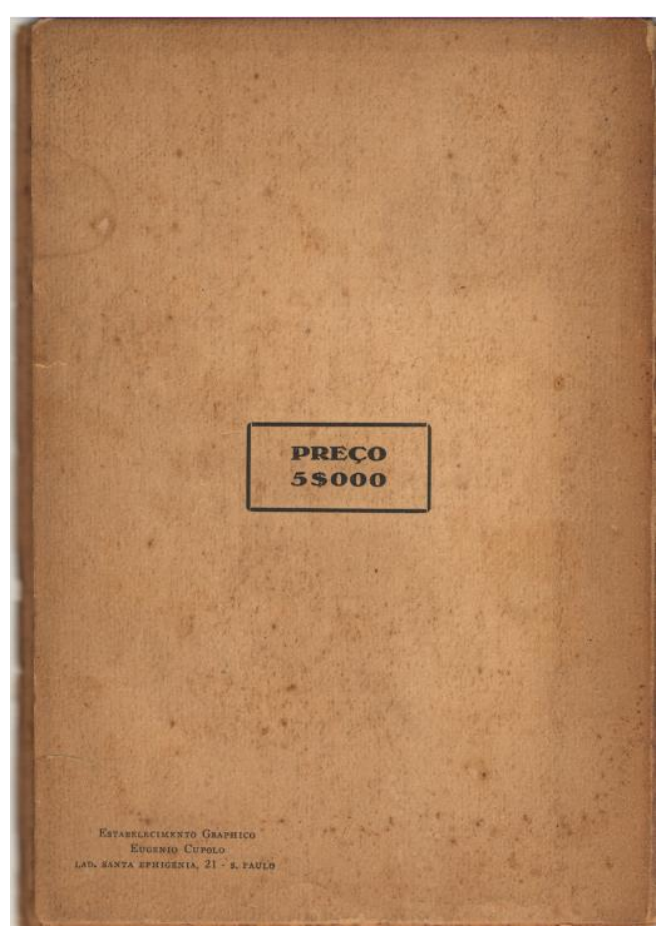

Figuras 2a/b: Capa e Contracapa da primeira edição do Clan do Jabuti, livro de poemas de Mario de Andrade. Note-se que não há registro de editora. Apesar do prestígio do poeta no futuro, a primeira edição foi feita pelo próprio autor na gráfica Eugenio Cupolo.

\section{MUSICA THEORICA}


c.

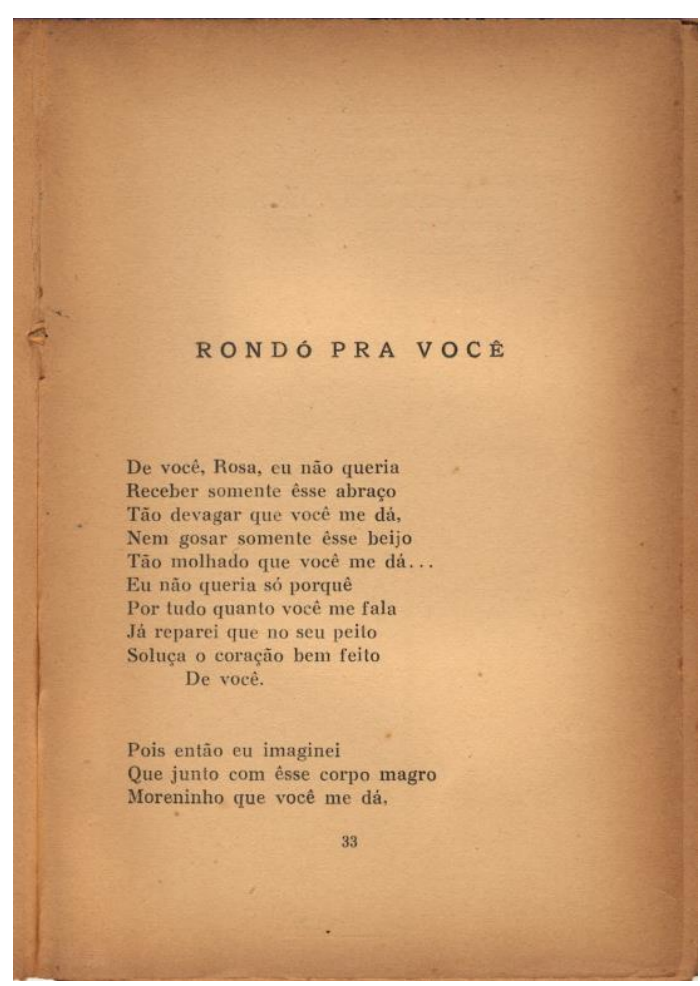

d.

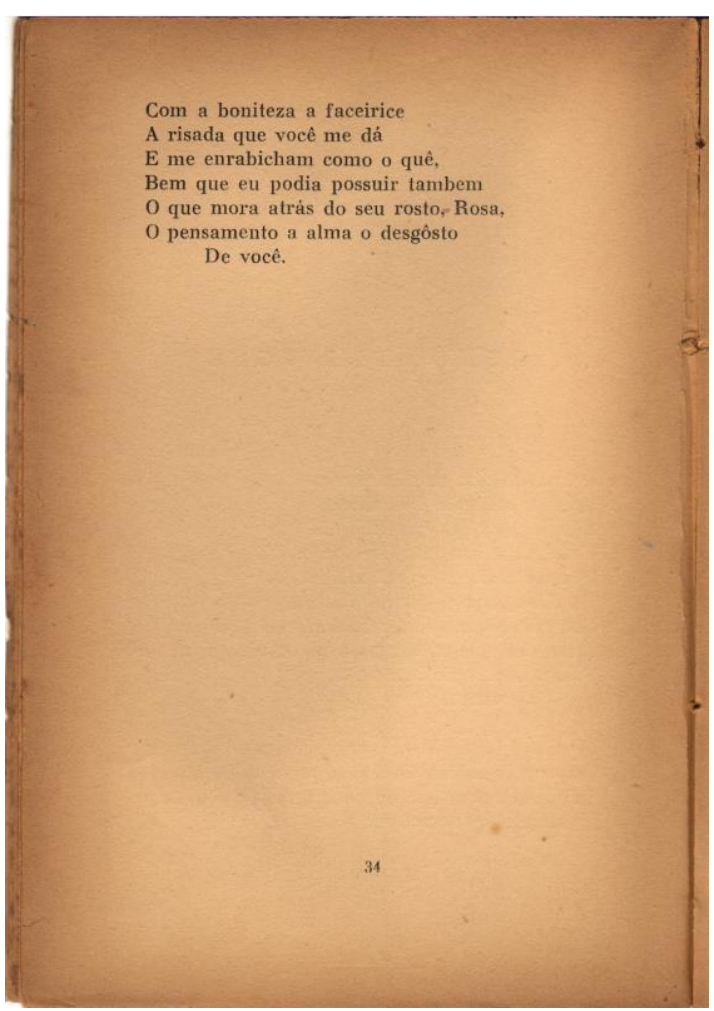

Figuras 2c/d: Páginas 33 e 34 da primeira edição do Clan do Jabuti, com o poema Rondó Pra Você de Mario de Andrade

\section{MUSICA THEORICA}

Revista da Associação Brasileira de Teoria e Análise Musical Journal of the Brazilian Society for Music Theory and Analysis @ TeMA 2017 - ISSN 2525-5541 